\title{
Intervenção fisioterapêutica na amiotrofia muscular espinhal tipo 1: revisão de
}

\section{literatura}

\author{
Physiotherapeutic intervention in spinal muscular amyotrophy type 1: literature review \\ Intervención fisioterapêutica em amiotrofia muscular espinal tipo 1: revisión de la literatura
}

Recebido: 01/09/2021 | Revisado: 09/09/2021 | Aceito: 13/09/2021 | Publicado: 14/09/2021

\author{
Márvina Barbosa da Silva Mouzinho \\ ORCID: https://orcid.org/0000-0002-7644-0438 \\ Instituto Educacional Santa Catarina-Faculdade Guaraí, Brasil \\ E-mail: marvina2212@gmail.com \\ Rebeca Lima de Souza Silva \\ ORCID: https://orcid.org/0000-0002-2005-970X \\ Instituto Educacional Santa Catarina-Faculdade Guaraí, Brasil \\ E-mail: rebecalimasouza7@gmail.com \\ Karla Camila Correia da Silva \\ ORCID: https://orcid.org/0000-0003-1538-7028 \\ Instituto Educacional Santa Catarina-Faculdade Guaraí, Brasil \\ E-mail:karlacamilac@yahoo.com.br
}

\begin{abstract}
Resumo
A Amiotrofia Muscular Espinhal (AME) é uma patologia de origem genética de herança autossômica recessiva, neuromuscular degenerativa. Acomete principalmente os neurônios motores do corno anterior da medula espinhal. De acordo com a idade de inicío das manifestações clinicas, e pelo comprometimento motor, a AME é classificada em quatro tipos (I a IV). O referido estudo de revisão literária tem como objetivo expor a etiologia, fisiopatologia, diagnóstico, tratamento e a importância da intervenção fisioterapêutica em pacientes portadores da Amiotrofia Muscular Espinhal, em especifico na AME tipo I. Na presente pesquisa foram considerados para criterios de inclusão artigos que envolvesse a tematica no que se refere á intervenção fisioterapêutica na Amiotrofia Muscular Espinhal tipo 1. A publicação dos dados coletados ocorreu entre o período de 2007 a 2021, em lingua portuguesa, inglesa e espanhola. O levantamento bibibliográfico foi realizado nas bases de dados: Scielo, Pubmed, PEDro, Lilacs e Google acadêmico, no período de março a outubro. No decorrer da pesquisa foi observado á intervenção físioterapêutica na Amiotrofia Muscular Espinhal em especifico na AME tipo 1. Concluindo que o modo de atuação da fisioterapia preconiza minimizar/retardar as manifestações clínicas que afetam o sistema musculoesquelético e as complicações no sistema respiratório, contribuindo para promover qualidade e prolongar a vida, e consequentemente evitando o óbito desses pacientes.
\end{abstract}

Palavras-chave: AME (Amiotrofia Muscular Espinhal); AME tipo I; Fisioterapia; Reabilitação.

\begin{abstract}
Spinal Muscular Amyotrophy (SMA) is a genetic disorder of autosomal recessive, degenerative neuromuscular inheritance. It mainly affects the motor neurons of the anterior horn of the spinal cord. According to the age of onset of clinical manifestations and motor impairment, EBF is classified into four types (I to IV). This literary review study aims to expose the etiology, pathophysiology, diagnosis, treatment and the importance of physical therapy intervention in patients with Spinal Muscular Amyotrophy, specifically in type I SMA. In this research, articles that were considered for inclusion criterious involved the theme with regard to physical therapy intervention in Spinal Muscular Amyotrophy type 1. The publication of the data collected took place between 2007 and 2021, in Portuguese, English and Spanish. The bibliographical survey was carried out in the following databases: Scielo, Pubmed, PEDro, Lilacs and Academic Google, from March to October. During the research, physiotherapeutic intervention was observed in Spinal Muscular Amyotrophy, specifically in type 1 SMA. Concluding that the mode of action of physiotherapy advocates minimizing/slowing down the clinical manifestations that affect the musculoskeletal system and complications in the respiratory system, contributing to promote quality and prolong life, and consequently preventing the death of these patients.
\end{abstract}

Keywords: AME (Spinal Muscular Amyotrophy); AME type I; Physiotherapy; Rehabilitation.

\section{Resumen}

La amiotrofia muscular espinal (AME) es un trastorno genético de herencia neuromuscular degenerativa autosómica recesiva. Afecta principalmente a las motoneuronas del asta anterior de la médula espinal. Según la edad de aparición de las manifestaciones clínicas y el deterioro motor, la LME se clasifica en cuatro tipos (I a IV). Este estudio de 
revisión literaria tiene como objetivo exponer la etiología, fisiopatología, diagnóstico, tratamiento y la importancia de la intervención fisioterapéutica en pacientes con Amiotrofia Muscular Espinal, específicamente en AME tipo I. En esta investigación, los artículos que fueron considerados para criterios de inclusión involucraron el tema con Respecto a la intervención de fisioterapia en Amiotrofia Muscular Espinal tipo 1. La publicación de los datos recolectados se realizó entre 2007 y 2021, en portugués, inglés y español. El relevamiento bibliográfico se realizó en las siguientes bases de datos: Scielo, Pubmed, PEDro, Lilacs y Academic Google, de marzo a octubre. Durante la investigación se observó intervención fisioterapéutica en Amiotrofia Muscular Espinal, específicamente en AME tipo 1. Concluyendo que la forma de trabajo de la fisioterapia es minimizar / retrasar las manifestaciones clínicas que afectan el sistema musculoesquelético y las complicaciones en el sistema respiratorio, contribuyendo a promover la calidad y prolongar la vida, y consecuentemente prevenir la muerte de estos pacientes.

Palabras clave: AME (Amiotrofia muscular espinal); AME tipo I; Fisioterapia; Rehabilitación.

\section{Introdução}

A atrofia muscular espinhal (AME) é uma patologia de origem genética caracterizada pela atrofia muscular secundária a degeneração de neurônios motores localizados no corno anterior da medula espinhal. É classificada por tipos (I, II, III e IV), conforme o nível de acometimento, sendo que AME tipo I é a mais grave desenvolvida na infância e a tipo IV mais branda, comumente presente na fase adulta. (Sousa \& Alcântara, 2017)

No que diz respeito ao tratamento da doença em geral, se dá pela junção medicamentosa/farmacológica e uma equipe multidisciplinar, onde na mesma possui o fisioterapeuta, profissional que é devidamente capacitado para intervir desde os quadros graves a leves. Entretanto, a fisioterapia tem seu brilhante papel na AME tipo I, pois atua diretamente nos maiores comprometimentos, sendo eles cardiorrespiratório e neuro-motor apresentado pelos pacientes. (Baione \& Ambiel, 2010)

Sendo assim, o objetivo do presente estudo de revisão literária é expor a etiologia, fisiopatologia, diagnóstico, tratamento e a importância da intervenção fisioterapêutica em pacientes portadores de Atrofia Muscular Espinhal, em especifico na AME tipo I.

\section{Metodologia}

Este estudo é uma revisão bibliográfica, descritiva e exploratória, de abordagem qualitativa. Tendo como base para sua discursão teórica, artigos científicos e demais produções intelectuais. Foram considerados os critérios de inclusão: artigos e produções intelectuais publicadas, compreendendo o período de 2007 a 2021, em língua portuguesa, inglesa e espanhola. Foram excluídos os estudos que não apresentaram claramente o percurso metodológico, relatórios institucionais e os que não possuíam conteúdo relacionado ao tema e/ou contribuíram para o alcance do objetivo desse estudo. O levantamento bibliográfico foi realizado nas bases de dados: Scielo, Pubmed, PEDro, Lilacs e Google acadêmico, no período de março a outubro. (Pereira A.S. et al, 2018)

\section{Revisão de Literatura}

\subsection{Amiotrofia muscular espinhal}

A descrição da amiotrofia muscular espinhal ocorreu na segunda metade do século XIX, em 1890 pelo neurologista austríaco Guido Werding que fez suas primeiras observações da patologia apresentando a sua forma mais grave. No ano seguinte em 1891, o também neurologista alemão Johann Hoffaman descreveu a amiotrofia muscular espinhal em crianças de uma mesma família, desde então a doença passou identificada como AME do tipo I ou doença de Werding - Hoffaman. (Sousa \& Alcântara, 2017; Baione \& Ambiel, 2010)

Lisa Welander e Erik Kugelberg neurologistas suecos em 1956 identificaram uma forma menos agressiva da doença a chamando de amiotrofia muscular juvenil ou doença Kugerlberg - Welander. (Cura Ame, 201?)

Em 1995 a Dra. Judith Melki juntamente com seu grupo do hospital Necker Enfants Melades em Paris, realizaram 
estudos para identificação do gene responsável pela doença. A partir de então, a amiotrofia muscular espinhal (AME) passou a ser definida como uma patologia de origem genética de herança autossômica recessiva, neuromuscular degenerativa progressiva e debilitante com ocorrência em 1 a cada 10.000 nascidos vivos. (Tizzano, 2007)

A patologia acomete principalmente os neurônios motores do corno anterior da medula espinhal, os músculos respiratórios, bulbares e os paravertebrais são geralmente comprometidos, em contrapartida os músculos faciais e oculares tem suas funções preservadas. Todos esses fatores irão resultar em fraqueza simétrica, atrofia e hipotonia de grupos musculares proximais de cintura escapular e cintura pélvica, associado com as fasciculações e arreflexias tendínea. (Silva \& Mejia, 2013)

De acordo com a idade de início das manifestações clinicas, e pelo comprometimento motor, podemos classificar a AME em quatro tipos:

AME tipo I: Também conhecida como doença de Werding- Hoffaman, irá acometer precocemente crianças de 0 a 6 meses de idade, provocando uma diminuição de movimentos e de tônus musculares, comprometimento do controle da coluna cervical, levando a ausência de habilidade do paciente sentar sem apoio, com dificuldade no sustento da cabeça, com choro e tosse fracos, fasciculações (movimentos anormais da língua), arreflexias (diminuição dos reflexos profundos). Com a fraqueza de tronco e membros, os músculos intercostais são afetados, o que vai resultar em um déficit fisiológico da mecânica respiratória. Embora os músculos intercostais são lesados, o diafragma a princípio é preservado. Antes de completarem 1 ano de idade essas crianças podem desenvolver a incapacidade no processo de deglutição ao se alimentarem, desencadeando um quadro de desnutrição. Nessa pouca idade o que pode levar ao óbito precoce são as severas complicações respiratórias associadas com as disfunções bulbares.

Mesmo que essas crianças apresentem uma expectativa de vida reduzida sendo menos de 2 anos, as inovações de tratamentos e estudos podem elevar as perspectivas de sobrevida desses pacientes. (Baione \& Ambiel, 2010; Tizzano, 2007; Silva \& Borgamann, 2021)

AME tipo II: Ou intermediária, as manifestações ocorrem por volta dos 6 a 18 meses de vida, ou podem surgir precocemente. Os pacientes com esse tipo de AME desenvolvem insuficiências respiratórias, conseguindo sentar-se sozinhos levantando em algumas situações, porém sempre com auxílio. Para se locomover de forma independente é necessário o uso de dispositivo como cadeira de rodas. A fraqueza muscular terá início nos MMII e região proximal de tronco o que vai desencadear más formações estruturais como escoliose, e consequentemente pode originar uma patologia pulmonar restritiva. Alguns pacientes vão adquirir fraqueza bulbar, associada com a disfagia (dificuldade de engolir), resultando em um baixo ganho de peso. (Baoine \& Ambiel, 2010; Silva \& Rodrigues, 2019; Chrun et al., 2017)

AME tipo III: Também chamada de AME juvenil ou doença de Kugelberg - Welander, tem seu surgimento após os 18-24 meses, podendo ter início na adolescência ou na fase adulta. O paciente vai apresentar atraso no DNPM (Desenvolvimento Neuropsicomotor) relacionado à fadiga muscular de forma leve, fraqueza nas regiões proximais do quadril, resultando na maioria dos casos à necessidade do uso de cadeira de rodas para realizar a locomoção. Esses indivíduos não apresentam chances de adquirir escoliose, com preservação da sua mecânica respiratória com pouca ou nenhuma fraqueza dessa musculatura. (Zanoteli et al., 2020)

Quando esse tipo de AME manifesta-se antes dos 3 anos de idade, podemos classificá-la como AME IIIa, se após essa idade iniciar as manifestações, é classificada como AME IIIb. A diferença entre ambas é que, na AME IIIa os pacientes conseguem realizar uma deambulação até os 20 anos de idade, em contrapartida os pacientes com AME IIIb com a mesma faixa etária conseguem permanecer com essa função durante toda a vida. (Silva \& Rodrigues, 2019; Zanoteli et al., 2020)

AME tipo IV: Ainda não se compreende em que idade surgi esse tipo de AME. Para alguns autores a AME tipo IV tem início após 10 anos de idade, entretanto para outros, é apenas por volta dos 30 anos de idade. Os pacientes tem sintomas leves de fraqueza muscular, sem prejuízos respiratórios, realizando uma deambulação de forma independente, com expectativa 
de vida normal. (Baione \& Ambiel, 2010; Zanoteli et al., 2020)

\subsection{Fisiopatologia da AME}

A Amiotrofia Muscular Espinhal (AME) é provocada por um erro no cromossomo 5q13, levando uma mutação da proteína SMN (proteína que possibilita a sobrevivência do neurônio motor, protegendo e possibilitando a estruturação dos neurônios motores e dos núcleos motores do tronco encefálico), provocando nesta região uma duplicação invertida dos 4 genes. (Farooq \& Machenzie, 2013)

Para possibilitar o funcionamento adequado de $100 \%$ do gene da proteína SMN, é necessário um gene que forneça informações, e este é o gene SMN1, que em 1995 foi realizada a identificação da deleção homozigótica (desequilíbrio do cromossomo, por perda de um segmento cromossômico) do mesmo, o que levou os pesquisadores a conclusão que $95 \%$ dos pacientes com AME é ocasionado por esse erro cromossômico. (Tizzano, 2007; Chrun et al., 2017; Farooq \& Mackenzie, 2013)

A proteína SMN pode ser também produzida por um gene quase idêntico ao SMN1, o SMN2. A diferença entre ambos ocorre no nucleotídeo (responsável pela formação dos ácidos nucleicos do DNA e RNA) no exon 7 e 8 , isso porque no gene SMN1 o transcrito C é gerado de forma completa, enquanto no gene SMN2 esse transcrito C se transforma em T na posição 6 do exon 7, o que vai resultar na exclusão do exon 7. Dando origem a proteína SMN de forma diferente e incompleta de acordo com sua função fisiológica. O gene SMN2 pode produzir a proteína SMN cerca de 10-50\%, dependendo da quantidade de cópias e da gravidade da patologia. A ausência total dessa proteína SMN não permite a sobrevivência do indivíduo, pois irá impossibilitar a sobrevivência dos neurônios motores da medula espinhal. A AME geralmente ocorre em pessoas que herdam duas cópias defeituosas do gene SMN1 - uma herdada do pai e outra da mãe. (Winkelsas et al., 2020; Chrun et al., 2017; Zanoteli et al., 2020)

Pacientes não afetados pela AME tem essas 4 cópias dos genes em perfeita harmonia (2 cópias do SMN2 e 2 cópias do SMN1). E de acordo com a classificação e gravidade da AME o gene SMN2 possui sua quantidade definida: AME tipo Ipossui 2 cópias do gene SMN2 e nenhuma cópia do gene SMN1; AME tipo II- possui 3 cópias do gene SMN2 e nenhuma cópia do gene SMN1; AME tipo III e IV- possui as 4 cópias do gene SMN2. Sendo que, pessoas que apresentem 5 ou mais cópias do gene SMN2, apesar da ausência do gene SMN1 são considerados assintomáticos e protegidos contra a manifestação da doença. (Tizzano, 2007; Farooq \& Mackenzie, 2013; Zanoteli et al., 2020; Baione \& Ambiel, 2010)

\subsection{Diagnóstico da AME}

Há anos atrás, a forma de diagnosticar AME era por meio de exame com eletroneuromiografia e biopsia muscular. Porém, esse procedimento é muito doloroso para as crianças, além de que não eram capazes de fechar o diagnóstico de AME e retardava ainda mais as intervenções imediatas/preventivas.

A partir de então, outro método foi elaborado considerado o único exame que confirma o laudo de AME. O teste genético molecular. Orientado pelo Consenso de 2018 que se há alguma suspeita clínica, deve ser realizado imediatamente.

O teste consiste em uma investigação por técnicas, sendo o MLPA (Amplificação Multiplex de Sondas Dependente de Ligação) mais utilizado, que detecta a deleção do gene SMN1. Sendo que a ausência do éxon 7 nos dois alelos do gene SMN1 confirma o diagnóstico de AME, ocorrendo em 90 a 95\% dos pacientes. E em 5\% a 10\% dos pacientes a deleção de apenas um alelo do gene SMN1 e o outro apresenta mutação intragênica; muito mais raramente ainda há mutação intragênica em ambos os alelos.

Entretanto, caso seja localizada uma cópia completa do gene e tenha sinais clínicos de AME, deve-se realizar o sequenciamento do gene para detecção de mutações intragênicas. Para a confirmação do diagnóstico genético o conhecimento 
da quantidade de cópias do gene SMN2 também é importante, pois pode auxiliar no indicativo da severidade da doença e atuação terapêutica.

O diagnóstico no pré-natal também é possível desde que sejam em feto de famílias que já tiveram um filho acometido, adquirindo uma amostra de vilosidade coriônica, líquido amniótico ou sangue do cordão, mas a interpretação do resultado é difícil quando não se encontra deleção nos dois alelos.

Apesar do alto custo financeiro e não ser disponibilizado pelo SUS, o diagnóstico pré-implantacional também é um recurso que através do método de fertilização in vitro permite selecionar embriões sem mutação do gene SMN1. (Zanoteli et al., 2020)

A grande conquista para os portadores de AME quanto a diagnóstico precoce, foi a aprovação da lei PL 5043/2020 que torna obrigatório a triagem neonatal na rede de saúde pública, mas conhecido como teste do pezinho (realizado a partir de amostra de sangue coletada no calcanhar do recém-nascido) de modo ampliado, que antes detectava 6 patologias e atualmente incluiu a AME (e futuramente abrangerá mais de 53 doenças), concedido o direito legalmente em 23/03/2021. (Viana, 2021)

\subsection{Tratamento Medicamentoso}

Em 2016 foi aprovado pela FDA (Agência Federal do Departamento de Saúde e Serviços Humanos dos Estados Unidos), a comercialização do primeiro e único fármaco Spiranza com princípio ativo nusinersen, produzida pela empresa de biotecnologia norte-americana Biogen, para tratamento da Amiotrofia Muscular Espinhal. (Sousa \& Alcântara, 2017; Relatório do EPAR, 2017)

Esse medicamento vai atuar na retirada dos íntrons de um RNA imaturo, de forma que vai produzir um RNA maduro funcional. Ou seja, pacientes portadores da AME não podem produzir a proteína SMN suficiente. Essa proteína é responsável pela sobrevivência dos neurônios motores. A proteína SMN é codificada em dois genes: SMN1 e o SMN2. (Spinraza, 2021)

Quem apresenta essa patologia não possuem o gene SMN1, porém apresentam o gene SMN2 que vai ser responsável pela produção da proteína SMN de forma insuficiente para exercer sua função. A ação do Spiranza que é um oligonucleotídeo antisense sintético (tipo de material genético), vai possibilitar que o gene SMN2 seja convertido no gene ausente (SMN1) funcional, aumentando os níveis da proteína SMN no Sistema Nervoso Central (SNC). (Diretoria médica Biogen Brasil, 2018; Relatório do EPAR, 2017)

Com o uso do Spiranza, é possível obter melhora da força muscular e controle do avanço da patologia. Ao ser administrado na infância ou até mesmo antes do surgimento dos primeiros sintomas, a função motora é preservada, e desse modo a sobrevida desses pacientes, reduzindo o risco de morte, e consequentemente o uso de ventilação mecânica. (Castro et al., 2019)

O medicamento é adquirido perante receita médica, e o seu tratamento deve ser realizada por médicos e enfermeiros com experiência no procedimento. O spiranza está disponível em forma de solução injetável em frascos de $12 \mathrm{mg}$ por via intratecal (diretamente na medula espinhal, na parte inferior das costas). (Relatório do EPAR, 2017)

No Brasil, a medicação teve registro liberado pela ANVISA em agosto de 2017. É considerada uma das drogas de elevado custo. No dia 14 de março de 2019, o Ministério da Saúde solicitou a incorporação do medicamento no SUS pela Comissão Nacional de Incorporação de Tecnologias (CONITEC). A compra desse medicamento desde abril de 2019 ocorria por judicialização de entes governamentais. (Sousa \& Alcântara, 2017; Ministério da saúde, 2019)

\subsection{Tratamento fisioterapêutico}

Consta-se que a AME é uma patologia de grandes acometimentos sistêmicos, principalmente: cardiorrespiratório, osteomuscular e gastrintestinal, interferindo diretamente no desenvolvimento saudável do organismo. 
O portador e a família por sua vez, devem contar com uma equipe multiprofissional, sendo eles: fonoaudiólogo, nutricionista, médicos especialistas, enfermeiros especialistas, psicólogo e fisioterapeuta. Para retardar o progresso degenerativo da patologia.

Nesse processo, desde o diagnóstico até o tratamento ambulatorial, o fisioterapeuta é o profissional mais presente e necessário, sendo devidamente capacitado para atuar na minimização das complicações musculares e favorecer o aumento da expectativa de vida. (Ministério da saúde, 2019)

Entretanto, é importante salientar que ao estabelecer condutas fisioterapêuticas, o percurso natural da AME deve ser considerado, devido aos efeitos dos exercícios no sistema orgânico e as adaptações moleculares. Por isso, as atividades físicas na AME deve ser vista com o objetivo de melhorar a qualidade de vida do paciente e não como uma prática de exercícios exaustivos e forçados.

Sendo assim, dois critérios primordiais precisam ser obedecidos na implementação das atividades para os pacientes de AME: prevenção da atrofia por desuso e fadiga por uso excessivo dos neurônios motores remanescentes.

Em casos mais graves da patologia (AME TIPO I), a intervenção fisioterapêutica é de suporte, realizando exercícios passivos que visam a preservação do arco do movimento, flexibilidade, distensibilidade, com o objetivo de prevenir e retardar contraturas, encurtamentos. Além disso, a fisioterapia respiratória é de extrema importância nesse estágio, pois favorece a diminuição de secreções, de infecções, melhora função respiratória, melhora função pulmonar e dentre outros benefícios que serão expostos no decorrer do presente trabalho.

$\mathrm{Na}$ AME tipo 2, os comprometimentos do paciente começam nos membros superiores e progressivamente acometendo musculatura do tronco e a intervenção fisioterapêutica gira em torno de promover a realização de alongamentos nos tecidos articulares e peri-articulares, afim de prevenir contraturas e deformidades secundárias à imobilidade e posturas anormais. Além disso, alinhar e manter a postura adequada através de rolos, calhas, assentos adaptados e cadeiras sob medida é de fundamental importância, pois permite ao paciente participar ativamente de atividades sociais. Devido a falência respiratória ser a maior causa de morte dessas crianças, é necessário também o uso de incentivadores respiratórios de fluxo linear para a manutenção da capacidade vital, a eliminação de secreções brônquicas e a melhor eficácia do mecanismo de tosse.

Em casos menos severos como na AME tipo III, deve-se investir na preservação da função muscular através do treinamento do controle motor por meio de tarefas funcionais. Como o comprometimento motor proximal é maior, a realização dessas tarefas para as extremidades favorecem o desempenho das AVDs. É necessário também incentivar a capacidade aeróbica desses pacientes tendo o cuidado de não gerar sobrecarga, pois podem relatar dispnéia e fadiga durante a realização de algumas tarefas. Também é indicado aderir o uso de órteses funcionais que permitem executar funções específicas, sem sobrecarregar ou permitir o uso de compensações musculares e/ou articulares que possam trazer futuras contraturas e deformidades. (Guerra, 2019)

A AME tipo IV, apesar de não ser relatada em muitos estudos e estar presente na fase adulta (Orsini et al., 2008) os procedimentos cinesioterapêuticos são similares ao tipo III. Sendo que o objetivo da fisioterapia respiratória é prevenir o acúmulo de secreções e amenizar a redução do volume corrente, através de condutas visando expansão pulmonar, com auxílio de inspirometria de incentivo e direcionamento de fluxo aéreo para as áreas menos ventiladas do pulmão, associado com alongamento da musculatura acessória da respiração e torácica, favorecendo um maior alinhamento biomecânico do tórax. Visto que o treinamento dos músculos respiratórios melhora a função pulmonar, atenua o decrescimento do volume corrente e posterga o início da falência respiratória nesses pacientes. Porém, deve ser aplicada de forma cautelosa para não acelerar a fadiga dos músculos respiratórios pelo aumento da sobrecarga. (Guerra, 2019) 


\subsection{Tratamento fisioterapêutico na amiotrofia muscular espinhal tipo 1}

A causa mais frequente de óbito em crianças com AME são as complicações respiratórias, mais precisamente a IRA, devido ao desenvolvimento de pneumonias ou atelectasias. Decorrente principalmente por causa da fraqueza dos músculos respiratórios e bulbares que se responsabilizam pelo mecanismo da respiração, deglutição e fala.

Nos portadores de AME tipo 1, a fraqueza dos músculos respiratórios é generalizada, e os problemas respiratórios já ocorrem entre o nascimento e os 2 anos e meio de vida. Estas crianças normalmente entram em falência respiratória devido infecções advindas da acumulação de secreções, pois não possuem força para expelir. Além disso, a mecânica respiratória é completamente comprometida, pois se os músculos intercostais responsáveis pela expansão da caixa torácica são deficitários, o diafragma é sobrecarregado tornando-se o principal músculo usado para respirar. Adotando a chamada respiração diafragmática ou paradoxal. Nela ocorre uma assincronia do tórax e do abdômen durante a respiração: na inspiração o abdômen se movimenta para fora e o tórax para dentro. Podendo até mesmo adquirir um formato do tórax chamado de "tórax em sino" se não tiver intervenções imediatas e preventivas.

Outro comprometimento muito evidente nos pacientes de AME tipo I é a hipoventilação alveolar noturna (o aumento de $\mathrm{CO} 2$ no organismo) que é gerada devido ao relaxamento dos músculos respiratórios que é fisiologicamente normal no sono, porém associado à fraqueza muscular e à hipotonia severa, tornam a ventilação inadequada para realização das trocas gasosas, gerando sintomas como fadiga, dispneia, cefaleia matinal ou contínua, sonolência diurna, despertar noturno frequente com dispneia e taquicardia e entre outros, levando a casos gravíssimos e óbito. Por isso, a fisioterapia torna-se essencial nesse processo. Utilizando técnicas, meios e estratégias de avaliação e tratamento. Desde respiratórios a cinesioterapêuticos/funcionais.

Por se tratar de uma patologia rara de grandes comprometimentos, é necessário uma avaliação criteriosa e objetiva direcionada para a mecânica ventilatória. Deve-se avaliar a sintomatologia, o aumento da frequência respiratória, alterações do ritmo cardíaco e tensão arterial (pressão com que o sangue circula dentro das artérias), a simetria tóraco-abdominal (respiração paradoxal), a diminuição da eficácia da tosse, alterações da fala e da deglutição e a influência da posição na função respiratória. Tudo isso para aplicar as condutas de tratamento de forma efetiva.

A fisioterapia respiratória conta com um grande acervo de tratamentos que podem ser administrados nos pacientes com AME tipo I, onde os principais serão discorridos aqui. Entretanto, é importante lembrar que não há um protocolo único e específico. A aplicação dos recursos é mediante a gravidade da patologia associada a avaliação do profissional.

Um dos principais parâmetros que o fisioterapeuta precisa saber é como está a função pulmonar desses pacientes, podendo ser mensurada pelo ventilômetro, um recurso que quantifica a capacidade pulmonar vital e a capacidade vital forçada, muito importante para determinar se ele precisará de VNI noturna devido a hipoventilação alveolar. Para mensuração da força muscular, utiliza-se o manovacuômetro que é capaz de avaliar as pressões máximas, inspiratória (PImáx), que é uma medida negativa e a expiratória máxima (PEmáx) que é uma medida positiva realizada pelos músculos respiratórios.

O pico de fluxo expiratório (PFE) e pico de fluxo de tosse (PFT) mensurados pelo Peak Flow, também são parâmetros de avalição fisioterapêutica importantes, pois avaliará se a tosse é eficaz ou não e o PFT é o melhor indicador para remoção do tubo de traqueostomia, caso esse paciente tenha sido submetido ao procedimento, porém, os recursos fisioterapêuticos atuam de forma a retardar o uso de TQT, visto que a mesma favorece o surgimento de hemorragias, enfisema, lesão tecidual e infeção precocemente.

Quando o paciente apresentar um quadro agudo de dificuldade respiratória e não for possível a monitorização não invasiva do $\mathrm{CO} 2$, realiza-se a análise dos gases respiratórios através da gasometria arterial para avaliar a eficácia ventilatória. Diante disso, o tratamento fisioterapêutico respiratório deve tanto preventivo e de reabilitação, tentando melhorar ou manter qualidade de vida dos pacientes. Sendo que seu principal intuito é evitar a insuficiência ventilatória insidiosa e aguda. 
No que diz respeito as intervenções fisioterapêuticas, é sabido que quanto mais grave o tipo de AME e quanto mais cedo o iniciar os sintomas, maior vai ser a necessidade de suporte ventilatório. No caso das crianças tipo I sempre necessitarão de suporte ventilatório sendo ele não invasivo (VNI) que é fornecido por meio da máscara nasal ligada ao equipamento. Nesse caso, a indicação é usar pressão positiva nas vias aéreas em modo binível (BiPAP). Ou ventilação invasiva por meio da intubação orotraqueal ou traqueostomia.

A indicação de utilização da VNI é para os pacientes que apresentarem sinais e sintomas de hipoventilação alveolar e um dos seguintes critérios: $\mathrm{PaCO} 2$ maior ou igual a $45 \mathrm{mmHg}$, oximetria noturna com saturação do oxigênio em $88 \%$ ou menos por 5 minutos consecutivos, pressões inspiratórias máximas menores que $60 \mathrm{cmH} 2 \mathrm{O}$ ou capacidade vital forçada inferior a 50\% do previsto. Ou seja, característico dos AME tipo I. E sendo assim, a instituição da VNI deve ser fornecida de forma preventiva logo quando é diagnosticado e na presença de padrão paradoxal, taquipneia, sinais e sintomas sugestivos de hipoventilação alveolar e de desconforto respiratório. Quanto as interfaces para se utilizar existem vários tipos, porém para as crianças com AME tipo I a mais indicada é a nasal. A facial é contraindicada por causa do alto risco de sufocamento com salivas e secreções.

Os equipamentos que prestarão essa assistência aos pacientes com AME tipo I (sendo manuseados pelo fisioterapeuta) são: o BiPaP que é ventilador com suporte pressórico em modo binível que fornece dois níveis de pressão positiva nas vias aéreas podendo identificar o ciclo respiratório normal do paciente e desempenhar com ele, ou também realizar o ciclo quando o indivíduo estiver dormindo profundamente e não estiver respirando de forma correta sozinho. Sendo que a configuração recomendada é: IPAP entre 16 e 26 - pressão de suporte superior a $10 \mathrm{cmH} 2 \mathrm{O}$, EPAP entre 4 e 6 , frequência respiratória entre 18 e 35, de acordo com a basal para a idade e tempo inspiratório entre 0,5 e 1,5s, baseado na idade e na frequência respiratória.

O Cough Assist é uma máquina de tosse que apesar do alto custo monetário, traz excelentes benefícios nos pacientes com AME tipo I, pois seu quadro fisiopatológico não possibilita uma tosse satisfatória para expulsão das secreções. Por isso, o recurso fornece pressão positiva (insuflação) seguida por uma rápida pressão negativa (exsuflação), ou seja, manda ar para os pulmões com uma pressão pré-definida, em seguida aspira o ar dos pulmões com uma pressão pré-definida também. Isso ajuda a produzir uma tosse mais eficaz, mantendo a higiene das vias aéreas. Essas pressões de insuflação e exsuflação podem ser ajustadas de acordo com o conforto do paciente. Sendo que normalmente são usadas pressões entre $40 \mathrm{cmH} 2 \mathrm{O}$ a $60 \mathrm{cmH} 2 \mathrm{O}$ para remover secreções.

A indicação de uso para portadores de AME tipo I é diário, e em alguns casos mais de uma vez por dia. Geralmente, são usados de 3 a 5 ciclos, com 5 respirações em cada ciclo. A secreção deve ser aspirada entre um ciclo e outro. Em casos de resfriados, o uso da máquina de tosse deve ser intensificado conforme a necessidade do quadro.

Outro recurso necessário para os pacientes com AME tipo I é o AMBÚ (ressuscitador manual), principalmente em casos de emergências, pois ele é utilizado para: ventilação manual no caso de intercorrências clínicas como dessaturação grave e parada respiratória e em casos de falha do ventilador mecânico, auxilia na tosse e favorece expansão pulmonar através do empilhamento de ar/ insuflação passiva.

O oxímetro de pulso também é importante estarem constantemente, pois se a saturação dos pacientes com AME for inferior a 95\% já precisam de suporte respiratório extra. Além de que se a frequência cardíaca estiver acima do habitual do paciente e do normal para a idade deve ser averiguada, podendo sugerir quadro de infecção ou fadiga muscular.

Para ajudar umidificar as vias aéreas e a fluidificar as secreções, auxiliando na desobstrução das vias aéreas e a higiene brônquica, utiliza-se nebulizadores.

Outras intervenções fisioterapêuticas essenciais nos pacientes de AME tipo I, são os cuidados cinesioterápicos (fisioterapia motora), pois a fraqueza muscular faz com que diminui a mobilidade normal do corpo, o que favorece os encurtamentos musculares, chegando a perder sua funcionalidade. Sendo assim, o fisioterapeuta irá trabalhar de maneira que 
controle as deformidades e controle a função desses pacientes.

Os alongamentos e mobilizações articulares são recursos utilizados atenuar os encurtamentos, sendo que as regiões mais acometidas são: plantas dos pés, tornozelos, joelhos, quadris, cotovelos e pulsos. Por isso, os principais músculos a serem trabalhados são: flexores de punhos e dedos, inclinadores e rotadores laterais do pescoço, bíceps, tríceps, flexores de quadril, adutores, abdutores, pronadores, abdominais, peitorais e entre outros. Sendo que esses exercícios de alongamentos estáticos devem durar pelo menos 60 segundos por grupo muscular e devem ser realizados, no mínimo, 5 vezes por semana. Uma média de frequência diária ideal.

O posicionamento dos pacientes com AME tipo I também deve ter um cuidado especial, alterando a mudança de decúbito (lateral, ventral, dorsal) de $2 \mathrm{em} 2$ horas, acoplando apoios (coxins, travesseiros e outros) que favoreçam a posição adequada evitando feridas, desconforto e sobrecarga. É necessário também estimular a posição sentada mesmo que seja por menos tempo, mas garantir a mobilidade visto que provoca inúmeros benefícios vasculares. Outro posicionamento indispensável é o ortostatismo por um período de 1 hora, de 5 a 7 vezes por semana, pois é benéfico na formação óssea (prevenção da osteopenia), no trânsito gastrointestinal, socialização e principalmente alonga membro inferior.

Outro recurso muito utilizado para prevenção de deformidades, são as órteses que precisam ser prescritas pelo ortopedista e fisioterapeuta segundo a necessidade específica do paciente. Entretanto as mais utilizadas são: tala suropodálica ou AFO (ankle-foot orthosis), tala extensora de joelhos, faixa adutora, órtese tóraco-lombar-sacral com abertura abdominal (OTLS - colete rígido), colete flexível, órtese de punho e dedos e órtese de cotovelo.

O tipo de exercício a ser realizado com os pacientes com AME tipo I, serão propostos diante da avaliação clínica do fisioterapeuta que aplicará ou de forma passiva, assistida ou até mesmo ativa. Dependendo do quadro apresentado e da necessidade exposta. (Zanoteli et al., 2020; Mélo et al., 2017; Gonçalves \& Bach, 2019)

\section{Considerações Finais}

A AME tipo I é uma patologia complexa e muita desafiadora. O seu diagnóstico provoca mudanças tanto na vida do portador quanto de seus familiares. Porém, com o passar dos anos, com crescimento e difusão da ciência, realizou-se muitos estudos para compreender sua etiologia e quais intervenções deveriam ser feitas. E desde então, surgiram novas formas de tratamento, sendo um deles a atuação da fisioterapia que intervém para minimizar/retardar as manifestações clínicas que afetam o sistema musculoesquelético e as complicações no sistema respiratório, contribuindo para promover qualidade e prolongar a vida, e consequentemente evitando o óbito desses pacientes.

Entretanto, ainda se faz necessário investir em pesquisas científicas que visam obter maiores resoluções farmacológicas, bem como terapêuticas.

\section{Referências}

Baioni, M. T. C., \& Ambiel, C. R. (2010). Spinal muscular atrophy: diagnosis, treatment and future prospects: Atrofia muscular espinhal: diagnóstico, tratamento e perspectivas futuras (Artigo de revisão). Sociedade Brasileira de Pediatria, file://C:/Users/63984/Desktop/AME(Amiotrofia\% 20Muscular\%20Espinhal)/AME-\%20Diagnosticos, \%20tratamento\%20e\%20perspectivas\%20futuras.pdf

Castro, S. F. R., Marin, S. M., Sá, N. F., \& Palácio, G. S. (2019). Análise do uso do Medicamento SPINRAZA Associado à Fisioterapia na Qualidade de Vida de Indivíduos com Atrofia Muscular Espinhal (Artigo cientifico). Centro Universitário-UNICESUMAR, http://rdu.unicesumar.edu.br/bit stream/123456789/3954/1/RAFAELLY\%20FILOMENA\%20SOUZA\%20DE\%20CASTRO.pdf

CURA AME. (201?). História de la AME: Un poco de história sobre la Atrofia Muscular Espinal. Plataforma divulgativa de lucha por uma curación para la Atrofia Muscular Espinal. Espanha. https://curaame.wordpress.com/que-es-la-ame/historia-de-la-ame/

Chrun, R. L., Costa, C. R. L., Miranda, G. S., \& Almeida, M. F. (2017). Atrofia muscular espinhal tipo I: aspectos clínicos e fisiopatológicos (Artigo cientifico). Universidade do Estado de Mato Grosso, MT, Brasil. https://www.revistas.usp.br/revistadc/article/view/116499

Diretoria Médica Biogen Brasil. (2018). Atrofia Muscular Espinhal 5q (AME 5q) (Material informativo). Biogen, Rio de Janeiro, RJ, Brasil. file://C:/Users/63984/Desktop/AME(Amiotrofia\%20Muscular\%20Espinhal)/Biogen-\%20Spiranza.pdf 
Farooq, T. F., Holcik, M., \& Mackenzie, A. (2013). Spinal Muscular Atrophy: Classification, Diagnosis, Background, Molecular Mechanism and Development of Therapeutics. (Artigo científico). IntechOpen, Shard London Bridge, Reino Unido. https://www.intechopen.com/books/neurodegenerativediseases/spinal-muscular-atrophy-classification-diagnosis-background-molecular-mechanism-and-development-of-t

Gonçalves, R. M., \& Bach, R. J. (2019). Cuidados respiratórios e suporte ventilatório na atrofia muscular epinal (Artigo científico). Instituto Nacional de Atrofia Muscular Espinhal, https://iname.org.br/wp-content/uploads/2019/12/Artigo-Cuidados-Respirato\%CC\%81rios-na-AME-Miguel-Gonc\%CC\%A7alvesJohn-Bach.pdf

Guerra, C. S. N. M. (2019). A importância da fisioterapia em pacientes portadores de amiotrofia muscular espinhal (AME) (Artigo científico). CEAFI Pontífica Universidade Católica,. https://ceafi.edu.br/site/wp-content/uploads/2019/05/a-importncia-da-fisioterapia-em-pacientes-portadores-de.pdf

Mélo, M. T., Duarte, M. H. P., \& Coutinho, G. B. (2017). Atuação fisioterapêutica na atrofia muscular espinhal: uma revisão de literatura (Artigo científico). II Congresso Brasileiro de Ciências de Saúde, https://www.editorarealize.com.br/index.php/artigo/visualizar/29113

Ministério da Saúde. (2019). Nusinersena para Atrofia Muscular Espinhal $5 q$ (Relatório de Recomendação). CONITEC-Comissão Nacional de Incorporação de Tecnologias no SUS, http://conitec.gov.br/images/Relatorios/2019/Relelatorio_Nusinersena_AME5q_2019.pdf

Orsini, M., Freitas, M. R. G., Sá, C. R. M., Mello, P. M., Botelho, P. J., Antonioli, S. R., Santos, V. V., \& Freitas, R. G. (2008). Uma revisão das principais abordagens fisioterapêticas nas atrofias musculares espinhais (Artigo científico). Universidade Federal Fluminense https://www.arca.fiocruz.br/bitstream/ici ct/10651/2/Uma\%20Revis\%C3\%A3o\%20das\%20principais\%20abordagens\%20fisioterap\%C3\%AAuticas\%20nas\%20atrofias\%20musculares\%20espinhais.p df

Pereira, S. A., Shitsuka, D. M., Parreira, J. F., \& Shitsuka, R. (2018). Metodologia da pesquisa científica. https://repositorio.ufsm.br/bitstream/han dle/1/15824/Lic_C omputacao_Metodologia-Pesquisa-Cientifica.pdf?sequence=1

Relatório do EPAR destinado ao público. (2017). Spiranza- Nusinersen (Artigo Cientifico). European Medicines Agency, London, Reino Unido.https://www.ema.europa.eu/en/documents/overview/spinraza-epar-summary-public_pt.pdf

Silva, A. E., \& Mejia, M. P. D. (2013). Abordagem fisioterapêutica na atrofia muscular espinhal tipo I (Artigo Cientifico). Faculdade FAIPE, Cuiabá, MT, Brasil. https://portalbiocursos.com.br/ohs/data/docs/99/69-Abordagem_fisioterapYutica_na_atrofia_muscular_espinhla_tipo_I.pdf

Silva, S. F., \& Borgamann, A. D. (2021). Intervenção Fisioterapêutica na Atrofia Muscular Espinhal: Uma Revisão Bibliográfica (Dissertação de Mestrado). Universidade do Sul de Santa Catarina, Palhoça, SC, Brasil. https://periodicos.unifesp.br/index.php/neurociencias/article/view/11029

Silva, S. F., \& Rodrigues, P. M. J. (2019). Intervenção Fisioterapêutica Na Atrofia Muscular Espinhal: Uma Revisão Bibliográfica (Trabalho de conclusão de curso). Universidade do Sul de Santa Catarina, SC, Brasil. https://www.riuni.unisul.br/bitstream/handle/1 2345/8236/TCC\%20FINALIZADO\%20\%28 2\%29.pdf? sequence $=1$ \&isAllowed=y

Sousa, S. K., \& Alcântara, P. F. P. (2017). Atrofia Muscular Espinhal (AME): Atrofia Muscular Espinhal no Brasil (Trabalho de conclusão de curso). Centro Universitário ICESP, Brasília, DF, Brasil. http://nippromove.hospedagemdesites.ws/anais_simposio/arquivos_u p/documentos/artigos/fee 1465d0ae7305e7264bcfe e18ed3a8.pdf

Spinraza. (2021). A treatment for children and adults with spinal muscular atrophy (SMA) (Guia de apoio e suporte). Biogen, Estados Unidos, EUA. https://www.spinraza.com/en_us/home/taking-spinraza/find-a-treatment-center.html

Tizzano, F. E. (2007). Atrofia Muscular Espinal: Contribuciones para el Conocimento, Prevención Y Tratamiento de la enfermedad y para la família (Tese Doutorial). Instituto de Pesquisa do Hospital de la Santa Cruz e San Pablo, Barcelona, Espanha. http://riberdis.cedd.net/bitstream/handle/11181/29 81/Atrofia_muscular_espinal.pdf?sequence=1\&rd=0031971593811070

Viana, C. (2021). Proposta torna teste do pezinho ampliado obrigatório na rede pública de saúde (Projeto de Lei). Câmara dos Deputados, Brasília, DF, Brasil. https://www.camara.leg.br/noticias/728378-proposta-torna-teste-do-pezinho-ampliado-obrigatorio-na-rede-publica-de-saude/

Winkelsas, M. A., Grunseich, C., Harmison,G. G., Chwalenia, K., Rinalde, C., Hammond, M. S., Johnson, K., Bowerman, M., Arya, S., Talbot, K., Wood, J. M., \& Fischbeck, H. K. (2020). Targeting the 50 untranslated region of SMN2 as a therapeutic strategy for spinal muscular atrophy (Artigo científico). Molecular Therapy Nucleic Acids, Oxford, Inglaterra, Reino Unido. https://www.ncbi.nlm.nih.gov/pmc/articles/PMC7851419/

Zanoteli, E., Vital, E., Holsapfel, A. S., Crippa, S. P., Polido, J. G., Zuccon, A., Marra, S., Loriato, L., Viana, C. F., Klein, A., Gonçalves, M., Godoi, A. J., \& Hernesmeyer, L. D. (2020). Atrofia Muscular Espinhal: Entender, Cuidar e Viver (Guia para famílias e profissionais). Instituto Nacional de Atrofia Muscular Espinhal, São Paulo, SP, Brasil. file:///C:/Users/63984/Desktop/AME(Amiotrofia\%20Muscular\%20Espinhal)/Livro-AME_Miolo_Book_SITE.pdf 